\title{
Management of Incisional Hernias at a Tertiary Centre
}

\author{
Jacob A Akoh* \\ Department of Surgery, Plymouth Hospitals NHS Trust, Derriford Hospital, United Kingdom
}

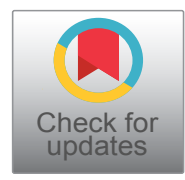

*Corresponding author: Jacob A Akoh FRCS (Gen) FACS, Consultant General/Transplant Surgeon \& Honorary Associate Professor, Plymouth Hospitals NHS Trust, Derriford Hospital, Level 04, Plymouth PL6 8DH, United Kingdom, Tel: +441-752432-650, Fax: +441-752-517-576, E-mail: Jacob.akoh@nhs.net

\begin{abstract}
Background and aims: About $10-30 \%$ of patients undergoing laparotomy develop an incisional hernia. The aim of this study was to review the experience of incisional hernias at a tertiary institution to determine what factors might improve the outcome of care.

Materials and methods: All patients with incisional hernias who underwent repair at Derriford Hospital, Plymouth between 2009 and 2011 were included in the study. A retrospective review of elective and emergency cases; operative details of the index procedure and hernia repair; and postoperative events and outcome was performed. Analysis was performed using an Excel pivot table and tests of statistical significance performed using GraphPad Prism.

Results: There were 205 patients ( 116 females and 89 males) with an overall mean age of 59.14 years (range 19-95). Eighty percent did not have any radiological imaging whereas $15.7 \%$ (defect diameter \pm SD $12.93 \pm 6.37 \mathrm{~cm}$ ) underwent CT scan. Twenty (10.8\%) patients with an average defect size of $2.81 \pm$ $1.41 \mathrm{~cm}$ underwent suture repair of their hernias. One hundred twenty-one $(65 \%)$ patients had a synthetic mesh whereas 18 $(9.7 \%)$ had a biological and $27(14.5 \%)$ a mixture of different types of mesh to effect complex repairs. The mesh was inserted by onlay technique in $79.6 \%$ compared to sublay in $14.9 \%$. Incisional hernia repair was successful in $92 \%$ with $17.6 \%$ needing readmission and $10.3 \%$ a reoperation.

Conclusions: There is need for a validated classification system and a robust randomised control trial of incisional hernia repair comparing onlay and sublay techniques as a way of driving improvements in outcomes.
\end{abstract}

\section{Keywords}

Onlay mesh repair, Sublay mesh repair, Recurrence, Seroma, Incisional hernia

\section{Introduction}

Incisional hernia is a common complication of laparotomy. Increasing obesity in the population coupled with more elderly people undergoing surgery $[1,2]$ and the increasing application of more complex procedures serve to maintain the prevalence of incisional hernias. About 10 to $30 \%$ of all patients undergoing laparotomy develop an incisional hernia [3-6]. Despite results of a prospective, controlled, randomised blind study showing the computed likelihood of incisional hernia at one year of $1.5 \%$ in the prophylactic mesh group compared to $35.9 \%$ in the group without mesh closure [7]; only few surgeons take prophylactic measures such as use of mesh for closure of wounds at high risk in order to prevent incisional hernias. The direct hospital costs and indirect costs to society of using mesh relative to primary suture closure after elective laparotomy showed mesh to be more effective, less costly and overall more cost-effective [8]. Incisional hernias therefore remain a major issue for patients undergoing abdominal surgery. It is not surprising therefore that there is ongoing debate about whether repair of incisional hernias should remain in the purview of general surgeons or be handed over to specialist hernia surgeons.

The aim of this study was to review the experience of incisional hernias at a tertiary institution to determine what factors might improve the outcome of care.

\section{Methods}

All patients with incisional hernias operated at Derriford Hospital, Plymouth between January 2009 and December 2011 were included in the study. A retrospective review was performed to include elective and emergency cases; operative details of the index procedure and hernia repair; and postoperative events including wound events; surgical site infections (SSI) and outcome. To achieve this, a comprehensive review of

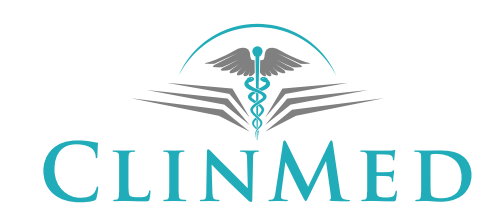

INTERNATIONAL LIBRARY

Citation: Akoh JA (2017) Management of Incisional Hernias at a Tertiary Centre. Int J Surg Res Pract 4:059. doi.org/10.23937/2378-3397/1410059

Received: October 12, 2017: Accepted: December 28, 2017; Published: December 30, 2017

Copyright: (C 2017 Akoh JA. This is an open-access article distributed under the terms of the Creative Commons Attribution License, which permits unrestricted use, distribution, and reproduction in any medium, provided the original author and source are credited. 
case notes, theatre database, patient demographics, previous medical/surgical history, surgical procedure, postoperative recovery was carried out. Information on these patients including biographical; original or index operation; risk factors such as obesity, smoking, diabetes; details of imaging, repair procedure; grade of surgeon performing repair; and outcome of repair were entered into a pro forma and then transferred to an Excel workbook. Repairs undertaken for primary ventral hernias were excluded. Also, four patients were excluded due to incomplete pertinent data.

Wound classification was retrospectively determined using the Association of Perioperative Registered Nurses (AORN) decision tree [9]. Re-admission referred to patients admitted to hospital within 30 days of discharge following incisional hernia repair. The hernia defect size was estimated either at imaging or at surgery and only the widest dimension of the defect was used. Hernias were classified according to the size of the defect (width) into small $(<4 \mathrm{~cm})$ moderate $(4-10 \mathrm{~cm})$, and large $(>10 \mathrm{~cm})[10]$. Complex incisional hernias $(>15 \mathrm{~cm})$ were repaired using a combination of biological (inserted intra-abdominally or in the sublay position) and synthetic mesh used to cover lateral defects after component separation. Biological meshes were used in patients at high risk of SSI or to bridge midline defects in patients not undergoing component separation for larger hernias.

Readmission was defined as admission within 30 days due to a complication of incisional hernia repair. Recurrence of the hernia was defined as a clinically detectable characteristic swelling or a radiologically diagnosed entity. Complications occurring within 30 days were recorded by the surgeon at discharge from the follow up clinic or on readmission. Diagnosis of seroma was made clinically and when necessary, augumented by imaging (ultrasound scan). Information on outcome of repair was obtained from multiple sources as detailed above. This was the case for all apart from six patients who had relocated from the area.

Analysis was performed using an Excel pivot table and tests of statistical significance performed using GraphPad Prism. P $<0.05$ was regarded as significant.

\section{Results}

There were 205 patients ( 116 females and 89 males giving a female/male ratio of 1.3:1) with an overall mean age of 59.14 years (range 19-95). The difference between the mean ages for females $(59.37 \pm 13.46)$ and males $(58.83 \pm 13.00)$ was not statistically significant $(0.5495 \% \mathrm{Cl}-3.145$ to $4.225 ; \mathrm{t}=0.2889 ; \mathrm{df}=203 ; \mathrm{p}=$ $0.773)$.

Table 1 shows the original procedures performed in 205 patients presenting with an incisional hernia. Colorectal procedures in 42 (20.5\%) and gynaecological procedures such as total abdominal hysterectomy with or without bilateral salpingo-oophorectomy and
Table 1: Index operation in 205 patients with incisional hernia.

\begin{tabular}{|l|l|}
\hline Procedure & Number (\%) \\
\hline Total abdominal hysterectomy & $29(14.2 \%)$ \\
\hline Appendectomy & $20(9.8 \%)$ \\
\hline Laparotomy & $19(9.3 \%)$ \\
\hline Open cholecystectomy & $16(7.8 \%)$ \\
\hline Hartmann's procedure & $14(6.8 \%)$ \\
\hline Anterior resection & $12(5.9 \%)$ \\
\hline Laparoscopic cholecystectomy & $10(4.6 \%)$ \\
\hline Colectomy/other & $8(3.9 \%)$ \\
\hline Laparotomy - peritonitis & $8(3.9 \%)$ \\
\hline Right hemicolectomy & $8(3.9 \%)$ \\
\hline Sigmoid colectomy & $7(3.4 \%)$ \\
\hline Caesarian section & $7(3.4 \%)$ \\
\hline Laparotomy - bowel resection & $6(2.9 \%)$ \\
\hline Abdominal aortic aneurysm repair & $5(2.4 \%)$ \\
\hline Laparotomy - trauma & $5(2.4 \%)$ \\
\hline Nephrectomy & $5(2.4 \%)$ \\
\hline Ventral hernia repair & $5(2.4 \%)$ \\
\hline Donor nephrectomy/transplant & $4(2.0 \%)$ \\
\hline Coronary artery bypass graft & $3(1.5 \%)$ \\
\hline Miscellaneous & $10(4.9 \%)$ \\
\hline Grand Total & 205 \\
\hline & \\
\hline
\end{tabular}

Table 2: Prevalence of risk factors among patients with incisional hernia.

\begin{tabular}{|l|l|l|l|}
\hline Parameter & $\begin{array}{l}\text { Total } \\
\text { Number }\end{array}$ & Positive & $\%$ \\
\hline BMI > 30 & 179 & 90 & 50.3 \\
\hline Emergency & 178 & 81 & 45.5 \\
\hline Recurrent hernia & 205 & 69 & 33.7 \\
\hline Contaminated/infected wound & 150 & 42 & 28.0 \\
\hline Smoking & 202 & 55 & 27.7 \\
\hline Musculoskeletal disorders & 202 & 29 & 14.4 \\
\hline Diabetes mellitus & 202 & 16 & 7.9 \\
\hline
\end{tabular}

caesarean sections in 36 (17.6\%) were the commonest procedures in these patients. The main indications for incisional hernia repair (in 202 patients) were pain in 94 (46.5\%); cosmetic reasons in 43 (21.3\%); a combination of pain and cosmesis in 30 (14.9\%); and obstructive symptoms in 11 (5.4\%). The prevalence of risk factors among the patients is shown in Table 2. Overall the mean BMI was $31.12 \pm 6.56$.

Eighty percent (158/197) of patients did not have any radiological imaging whereas $15.7 \%(31 / 197)$ underwent computed tomography scan and $4.1 \%(8 / 197)$ had ultrasound examination prior to repair of their hernias. The average transverse diameter \pm SD of the hernia defect for the three groups were $7.23 \pm 5.04 \mathrm{~cm}, 12.93$ $\pm 6.37 \mathrm{~cm}$ and $2.5 \pm 0.71 \mathrm{~cm}$ respectively. One hundred and fifty-nine (83.2\%) of 191 patients had prophylactic antibiotics. One hundred and eighty nine (92\%) patients underwent open repair whereas $16(8 \%)$ had laparoscopic repair of their incisional hernias.

Figure 1 shows the correlation between size of hernia defect $(\mathrm{cm})$ and the mean surgical operating time (minutes). The larger the defect, the longer the operation to repair the hernia took. Twenty $(10.8 \%)$ patients 
with an average defect size of $2.81 \pm 1.41 \mathrm{~cm}$ underwent suture repair of their hernias without the use of mesh. One hundred twenty-one (65\%) patients had a synthetic mesh whereas 18 (9.7\%) had a biological and 27 (14.5\%) a mixture of different types of mesh to effect complex repairs. Surgical site infection was more common in patients having biological mesh (8/18) than synthetic mesh $(11 / 121)$ - the difference was statistically significant $(p=$ 0.0005). Similarly, hernia recurrence was more common after repair with biological (4/18) than synthetic mesh $(8 / 121)-p=0.0506$.

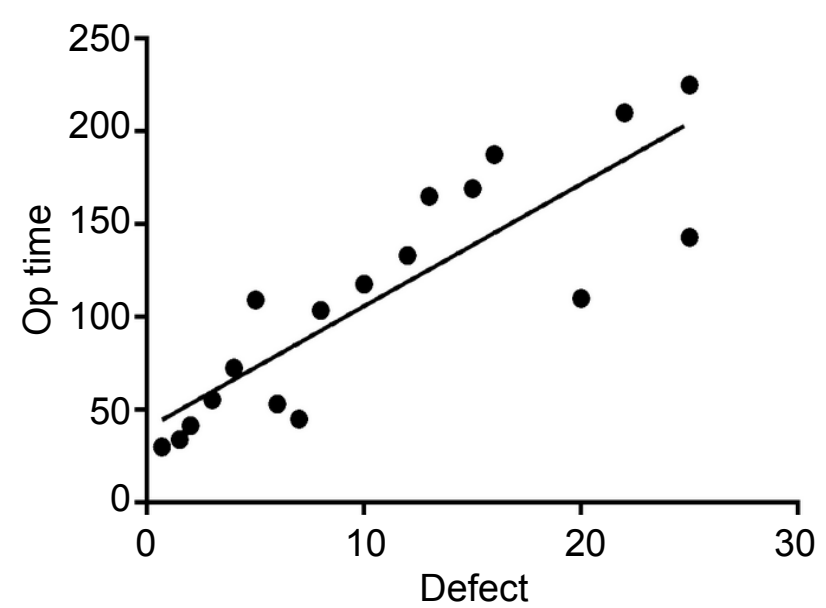

Figure 1: Correlation between average hernia defect $(\mathrm{cm})$ and mean operation time (minutes).

$F=43.70 ; d f n, d f d=1.16 ; p<0.0001 ;$ Equation: $Y=6.583^{*} X$ $+40.04$
The effect of mesh position on operation time is depicted in Figure 2. The mean \pm SD operating times were similar for both the onlay (108.85 \pm 60.09 minutes) and sublay (110.07 \pm 33.52$)$ techniques with no statistically significant difference $(t=0.1026 ; d f=169 ; p=0.918)$. However, 10 patients with larger, complex hernias repaired using a combination of onlay/sublay or onlay/ bridge techniques had significantly longer operation times (Figure 2). Four of these 10 had repair using the component separation technique - biological mesh in 'sublay' position and synthetic mesh to cover the defects in the external oblique aponeurosis.

Three of 27 (11.1\%) patients developed seroma following sublay mesh repair compared to 37 of 144 $(25.6 \%)$ following onlay repair (Table 3 ) but the difference was not statistically significant $\left(x^{2}\right.$ with Yates correction $=1.946 ; \mathrm{df}=1 ; \mathrm{p}=0.163)$. The main complications encountered in the 205 patients are detailed in Table 3. Surgical site infections comprised 19 superficial wound infections; three wound dehiscences; two infected haematomata and one deep infection involving an onlay mesh that had to be removed. Infection rates with mesh $(23 / 166)$ or suture $(2 / 20)$ repairs and in those using prophylactic antibiotics (24/159) compared to those not $(1 / 33)$ did not reach statistical significance $-x^{2}$ $=0.017 ; \mathrm{df}=1 ; \mathrm{p}=0.896$ and $\mathrm{x}^{2}=2.527 ; \mathrm{df}=1 ; \mathrm{p}=0.112$ respectively. One patient, a 62-year-old male, sustained bowel injury during dissection for a sublay mesh repair. His index operation was an emergency laparotomy for perforated appendicitis that was complicated by wound dehiscence. The bowel injury was not recognised during
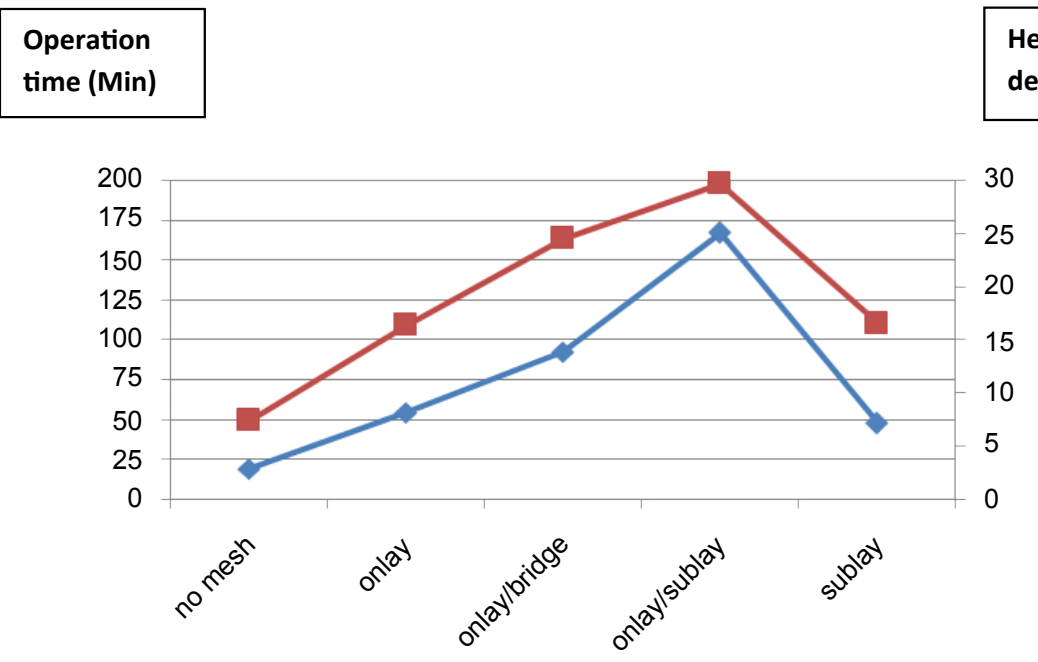

\begin{tabular}{|c|c|c|c|c|c|}
\hline Defect $(\mathrm{cm})$ & 2.8 & 8.1 & 13.8 & 25 & 7.4 \\
\hline Time (min) & 49 & 109 & 163 & 198 & 110 \\
\hline Number & 20 & 144 & 6 & 4 & 27 \\
\hline
\end{tabular}

Figure 2: Average operation time (primary Y-axis) and average defect size (secondary Y-axis) according to configuration of mesh repair. 
Table 3: Main complications following repair of 205 incisional hernias according to use and technique of insertion of mesh.

\begin{tabular}{|c|c|c|c|c|c|}
\hline Parameter & Number & SSI (\%) & Seroma (\%) & Haematoma (\%) & Recurrence (\%) \\
\hline Onlay & 144 & $22(15.3)$ & $37(25.7)$ & $7(4.9)$ & $8(5.6)$ \\
\hline Sublay & 27 & $1(3.7)$ & $3(11.1)$ & 0 & $5(18.5)$ \\
\hline Complex & 10 & $1(10)$ & $4(40)$ & $1(10)$ & $1(10)$ \\
\hline No mesh & 20 & $1(5)$ & 0 & 0 & $2(10)$ \\
\hline Fisher's exact test ${ }^{\star}$ & & 0.1311 & 0.1371 & 0.5980 & 0.0353 \\
\hline
\end{tabular}

"Comparison of onlay and sublay mesh techniques only; SSI: Surgical Site Infection.

Table 4: Factors influencing length of hospital stay.

\begin{tabular}{|l|l|l|l|l|}
\hline Comparator & Number & $\begin{array}{l}\text { Mean Length of Stay } \pm \\
\text { Standard Deviation }\end{array}$ & $\begin{array}{l}\text { Difference of Mean (95\% } \\
\text { Confidence Interval) }\end{array}$ & Significance (t; df; $p$-value) \\
\hline Technique - lap & 16 & $2.8235 \pm 2.2212$ & -2.631 & $\mathrm{t}=2.1072 ; \mathrm{df}=202 ;$ \\
open & 188 & $5.4545 \pm 5.0949$ & $(-5.0928$ to -0.1691$)$ & $\mathrm{p}=0.0363$ \\
\hline Mesh - biological & 17 & $10.6666 \pm 6.4443$ & -6.6501 & $\mathrm{t}=7.3671 ; \mathrm{df}=134 ;$ \\
synthetic & 119 & $4.0165 \pm 2.8518$ & $(-8.4354$ to -4.8647$)$ & $\mathrm{p}=0.0001$ \\
\hline Mesh - onlay & 144 & $5.3402 \pm 4.4220$ & 2.044 & $\mathrm{t}=2.3513 ; \mathrm{df}=169 ;$ \\
sublay & 27 & $3.2962 \pm 2.0346$ & $(0.3278$ to 3.7601$)$ & $\mathrm{p}=0.0199$ \\
\hline Infection - no & 178 & $4.8820 \pm 4.8864$ & -2.425 & $\mathrm{t}=2.3726 ; \mathrm{df}=202 ;$ \\
yes & 26 & $7.3076 \pm 4.8908$ & $(-4.4414$ to -0.4097$)$ & $\mathrm{p}=0.0186$ \\
\hline
\end{tabular}

t: statistic; df: degrees of freedom.

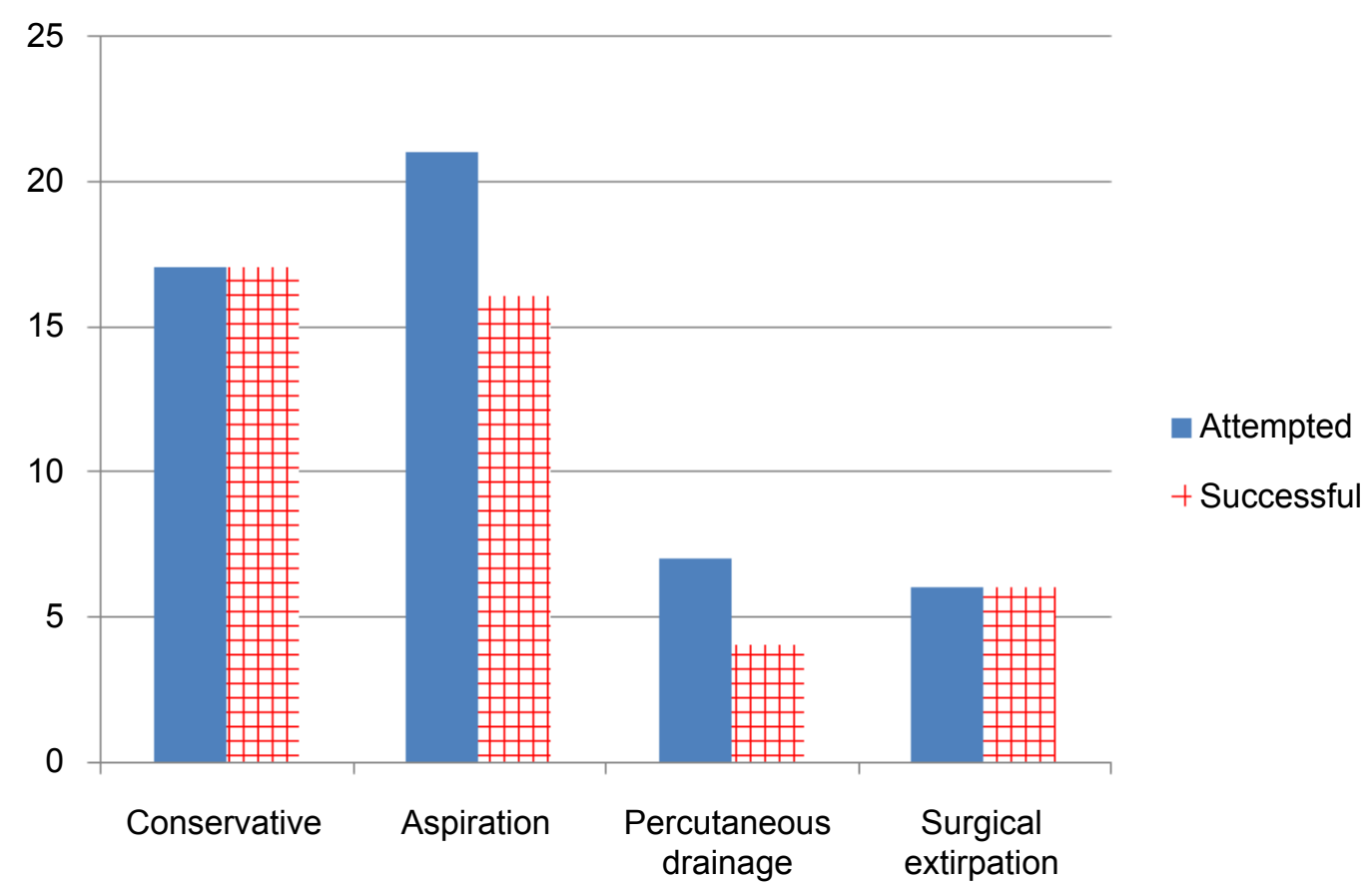

Figure 3: Management of seroma in 43 patients.

the hernia repair but presented with peritonitis postoperatively necessitating removal of the synthetic mesh. His hernia recurred 15 months later. Another patient developed an enterocutaneous fistula post onlay repair of his recurrent incisional hernia. He eventually underwent ileocolic resection to cure the fistula but his hernia recurred 14 months later.

Factors significantly impacting on the length of hospital stay during repair of incisional hernia are shown in Table 4 . One hundred and sixty-nine $(82.4 \%)$ of the patients were not readmitted following repair of their incisional hernias. Of the remaining, 18 (8.8\%) were readmitted due to seroma complications, 12 (5.9\%) due to infection/ wound dehiscence, two (1\%) each due to enterocutaneous fistula, haematoma and pain. The overall readmission rate was $17.6 \%$ with a reoperation rate of $10.3 \%$ (21 patients). The management of seroma comprised conservative treatment in 17; aspiration in 21 patients who had 70 episodes $(6 \times 1 ; 7 \times 2 ; 1 \times 3 ; 2 \times 4 ; 2 \times 5 ; 1 \times 7 ;$ and $2 \times 11$ ( 2 patients had 11 each); percutaneous drain age in seven; and surgical extirpation in six. The success rates of the various modalities for treating seroma are shown in Figure 3. Three patients in whom percutaneous drainage failed were eventually treated by surgical extirpation. Of the five not successfully treated by aspiration, two were treated by percutaneous drainage and three by surgical extirpation. 
The outcome of surgical repair of incisional hernia was known in 199 patients, of whom 183 (92\%) had an intact repair whereas $16(8 \%)$ had recurrence of their hernia after an average period of $9.15 \pm 6.53$ months. The size of the incisional hernia defect had no significant effect on whether the hernia recurred or not. The difference between the mean defect size for hernias that did not recur $(8.047 \pm 5.666)$ and those that recurred $(9.167$ $\pm 4.875)$ was not statistically significant $(-1.1295 \% \mathrm{Cl}$ -4.091 to $1.852 ; t=0.743 ; d f=198 ; p=0.458)$. Similar$l y$, there were neither significant differences between smokers and non-smokers $(p=0.535)$ nor diabetics and non-diabetics $(p=0.317)$ with regard to recurrence of incisional hernia. The recurrence rates were similar for consultants (14/174) and specialist registrars (2/25) $-x^{2}=0.000 ; p=0.994$; and for suture $(2 / 20)$ or mesh $(13 / 186)$ repairs $\left(x^{2}=0.002 ; d f=1 ; p=0.9684\right)$. Three patients had died by the end of the follow up period - an 84-year-old who died one year after open onlay repair; a 69-year-old dying 3 years after open repair and a 77-year-old dying three years after laparoscopic repair. None died from hernia related causes.

\section{Discussion}

The decision to use radiological assessment of incisional hernias in this centre was based on the size of hernia defect and anticipated level of difficulty with repair. Small hernias were probably investigated with UItrasonography to clarify diagnosis. Patients with large hernias were assessed by CT scan in order to determine the exact dimensions of the defect, content of sac, condition of the viscera, loss of domain and state of abdominal wall musculature. Such an approach as described here seems pragmatic and likely to be cost effective. Apart from addressing concerns about size of hernia defect, CT scan was particularly useful in patients whose previous operations were for sepsis (likelihood of severe adhesions) or cancer (exclude recurrent disease).

Several authors report excellent outcomes following mesh repair of incisional hernias [11-13]. The outcome of suture repair of incisional hernias, which is similar to mesh repair in this series, should be interpreted with caution as the type of hernias were different. However, suture repair (without mesh) of incisional hernia remains a controversial subject and the debate has been intensified by the report by Kokotovic and co-workers [14]. In a registry-based nationwide (Denmark) cohort study including 3242 patients (1119 open mesh (34.5\%); 366 open non-mesh (11.3\%); and 1757 laparoscopic mesh (54.2\%)), mesh repair was associated with a lower risk of recurrence. The cumulative incidence of mesh-related complications was $5.6 \%$ for open mesh repair and 3.7\% laparoscopic mesh repair whereas longterm repair-related complication rate for patients with non-mesh repair was $0.8 \%$. Kokotovic and co-workers [14] concluded that with long-term follow-up, the benefits attributable to mesh are offset in part by mesh-re- lated complications. This observation should be viewed through the prism of "selection bias" as larger, more complicated hernias are likely to be repaired with mesh and small, simple hernias with little likelihood of longterm problems tend to be repaired without mesh.

Onlay technique which was performed in 144 patients compared to 27 sublay repairs was the preferred technique in this centre during the period. Though the patients were not randomised, the average hernia defect $(8.12$ versus $7.14 \mathrm{~cm})$, mean age $(60.4$ versus 58.6 years) and BMI (31.5 versus $31.9 \mathrm{~kg} / \mathrm{m}^{2}$ ) were similar between the onlay and sublay groups respectively. The results of this series are comparable to those by Bender [3] who reported retro fascial mesh repair for incisional hernias in 538 patients. In the retromuscular position, the mesh is held closely against the deep surface of the muscles by the positive intra-abdominal pressure [11]. The main advantage of the sublay technique in this series was the shorter hospital stay but there are conflicting reports in the literature about the outcome of the sublay technique. Cobb, et al. [15] reported a higher recurrence rate after retrorectus mesh repairs with lightweight compared to mid-weight meshes but others disagree that the type of mesh makes any difference to the outcome $[13,16]$. Furthermore, a meta-analysis comprising a total of 1,948 patients (775 onlay operations and 1173 sublay operations) reported a lower recurrence rate and lower incidence of SSI after sublay repair [17]. As was the experience in the author's centre, Timmermans, et al. [17] did not find any significant difference in seroma and hematoma complications between the two groups. The higher recurrence rate associated with the sublay technique in this study is difficult to explain. It is most likely due to a selection bias. Anecdotal evidence from this centre suggests increasing use of the sublay technique in line with recent evidence [18], particularly among surgeons doing relatively higher numbers.

The success rate of incisional hernia repairs at this centre (intact repair at end of follow up) was $92 \%$ with $17.6 \%$ needing readmission and $10.3 \%$ undergoing reoperation. Laparoscopic surgery is generally associated with a shorter length of hospital stay when compared to open procedures as was the case in this study. Patients requiring the use of biological meshes already suffer a selection bias as they have complex or complicated hernias and are at high risk of surgical site infection and it is not surprising they stay longer in hospital. Elective incisional hernia repair is associated with high rates of readmission, reoperation and recurrence $[1,19]$. Apart from patients who had their mesh excised in response to complications following surgery, none of the other factors tested for their effect on hernia recurrence demonstrated any significant influence. The $8 \%$ recurrence rate reported in this study is much lower than the $21.1 \%$ by Helgstrand [1]. However, their reported 30 -day readmission and reoperation rates of $13.3 \%$ and 
$2.2 \%$ were better than the $17.6 \%$ and $10.3 \%$ respectively in this study.

Over 20 surgeons were involved in this series that performed few procedures, with three performing 112 $(55.6 \%)$ cases over the three years. Four patients with hernia defect of $25 \mathrm{~cm}$ underwent reconstruction of the abdominal wall using the component separation technique - all performed by the same surgeon. Even though the their procedures took much longer, their outcomes were satisfactory. It seems reasonable to suggest that only specialist surgeons should perform repair of large/ complex incisional hernias. The outcome of repair was not different between trainees and consultants. This is not surprising as most trainees performed the procedures under the supervision of their consultants. The surgeon effect on outcome could not therefore be objectively elucidated. Aquina and co-workers [20] reported that after adjusting for clinical factors, surgeons performing an average of over 36 repairs per year had significantly lower reoperation rates (HR $=0.59,95 \%$ Confidence Interval $(\mathrm{Cl})=0.48,0.72$ ) and operative efficiency. It would seem reasonable to suggest that preferential referral to high-volume surgeons may lead to improved outcomes and lower costs.

That inserting drains in the wound post hernia repair do not always prevent seroma formation is borne out by the randomised controlled trial of 42 individuals with large incisional hernias who following onlay mesh repair were allocated to either closed-suction drains or progressive tension sutures. The participants were subjected to clinical and ultrasound assessment to detect seroma and surgical wound infection at three time-points with no difference in the outcomes [21]. Clinical treatment of seromas is usually performed by repeated aspiration using an appropriately sized syringe depending on the amount of fluid to be evacuated. In some cases, an ultrasound examination can highlight the depth, volume, and extension of the fluid. In large seromas, percutaneous drainage is employed. Gioacchini, et al. [22] have described a simple device involving the use of basic materials such as a hypodermic needle, 20G syringe needle, and high-vacuum Redon drainage that allows effective drainage with a low risk of infection. Vasilakis and co-workers [23] described a new surgical approach in the definitive management of challenging cases of abdominal wall seroma following mesh repair - capsulectomy and scarification of the remnant pseudocapsule, for complex chronic abdominal wall seromas.

This study has a number of important limitations. Not all the patients had their index operations at Derriford hospital. This coupled with the fact that the total number of procedures, particularly laparotomies, during the period was not known made it difficult to establish the role or importance of risk factors. The main disadvantages of retrospective analyses with implications for missing data and selection bias were evident in this study.
Furthermore, the number of surgeons performing few procedures might have diluted the outcome measures. This study also highlights the difficulties of comparison of results due to the large diversity of heterogeneity of incisional hernias managed by different surgeons even in a single centre who do not use an accepted or validated classification system. Despite the foregoing, it is important to report raw data about this important and common problem in order to point the way to higher order studies geared to answering specific questions.

\section{Conclusion}

There is need for adoption of a validated system of classification of incisional hernias such as the one proposed by Muysoms, et al. [10]. Furthermore, a robust and contemporaneous randomised control trial of incisional hernia repair to compare onlay and sublay techniques may drive the improvement of outcomes of treatment.

\section{Conflict of Interest}

JAA has no conflict of interest to declare.

\section{Acknowledgements}

Grateful thanks to Mr Tahawar Rana, Clinical Fellow who helped with data collection.

\section{References}

1. Helgstrand F, Rosenberg J, Kehlet H, Jorgensen LN, Bisgaard $\mathrm{T}$ (2013) Nationwide prospective study of outcomes after elective incisional hernia repair. J Am Coll Surg 216: 217-228.

2. Yamada $T$, Okabayashi $K$, Hasegawa $H$, Tsuruta $M$, Abe Y, et al. (2016) Age, Preoperative Subcutaneous Fat Area, and Open Laparotomy are Risk Factors for Incisional Hernia following Colorectal Cancer Surgery. Ann Surg Oncol 23: S236-S241.

3. Bender JS (2016) Open retrofascial incisional hernia repair is a safe and effective operation. Am J Surg 211: 589-592.

4. Sanders DL, Kingsnorth AN (2012) The modern management of incisional hernias. BMJ 344: e2843.

5. Bucknall TE, Cox PJ, Ellis $H$ (1982) Burst abdomen and incisional hernia: A prospective study of 1129 major laparotomies. Br Med J (Clin Res Ed) 284: 931-933.

6. Eker HH, Hansson BM, Buunen M, Janssen IM, Pierik RE, et al. (2013) Laparoscopic vs. open incisional hernia repair: A randomized clinical trial. JAMA Surg 148: 259-263.

7. Caro-Tarrago A, Olona Casas C, Jimenez Salido A, Duque Guilera E, Moreno Fernandez F, et al. (2014) Prevention of incisional hernia in midline laparotomy with an onlay mesh: A randomized clinical trial. World J Surg 38: 2223-2230.

8. Fischer JP, Basta MN, Wink JD, Krishnan NM, Kovach SJ (2015) Cost-utility analysis of the use of prophylactic mesh augmentation compared with primary fascial suture repair in patients at high risk for incisional hernia. Surgery 158: 700-711.

9. AORN (2014) Surgical Wound Classification Decision Tree.

10. Muysoms FE, Miserez M, Berrevoet F, Campanelli G, Champault GG, et al. (2009) Classification of primary and incisional abdominal wall hernias. Hernia 13: 407-414. 
11. Schumpelick V, Klinge U, Junge K, Stumpf M (2004) Incisional abdominal hernia: The open mesh repair. Langenbecks Arch Surg 389: 1-5.

12. Kurzer M, Kark A, Selouk S, Belsham P (2008) Open mesh repair of incisional hernia using a sublay technique: Longterm follow-up. World J Surg 32: 31-36.

13. Li J, Ji Z, Zhang W, Li L (2015) The comparison of light weight mesh and standard mesh in incisional hernia repair with the open sublay technique: The results of a meta-analysis. Surg Laparosc Endosc Percutan Tech 25: 238-244.

14. Kokotovic D, Bisgaard T, Helgstrand F (2016) Long-term recurrence and complications associated with elective incisional hernia repair. JAMA 316: 1575-1582.

15. Cobb WS, Warren JA, Ewing JA, Burnikel A, Merchant M, et al. (2015) Open retromuscular mesh repair of complex incisional hernia: Predictors of wound events and recurrence. J Am Coll Surg 220: 606-613.

16. Ladurner R, Chiapponi C, Linhuber Q, Mussack T (2011) Long term outcome and quality of life after open incisional hernia repair-light versus heavy weight meshes. BMC Surg 11: 25.

17. Timmermans L, de Goede B, van Dijk SM, Kleinrensink GJ, Jeekel J, et al. (2014) Meta-analysis of sublay versus onlay mesh repair in incisional hernia surgery. Am J Surg 207: 980-988.

18. Holihan JL, Nguyen DH, Nguyen MT, Mo J, Kao LS, et al. (2016) Mesh location in Open Ventral Hernia Repair: A systematic review and network Meta-analysis. World J Surg 40: 89-99.

19. Nguyen MT, Li LT, Hicks SC, Davila JA, Suliburk JW, et al. (2013) Readmission following open ventral hernia repair: Incidence, indications, and predictors. Am J Surg 206: 942-948.

20. Aquina CT, Kelly KN, Probst CP, lannuzzi JC, Noyes K, et al. (2015) Surgeon volume plays a significant role in outcomes and cost following open incisional hernia repair. J Gastrointest Surg 19: 100-110.

21. Westphalen AP, Araújo AC, Zacharias $P$, Rodrigues ES, Fracaro GB, et al. (2015) Repair of large incisional hernias. To drain or not to drain. Randomized clinical trial. Acta Cir Bras 30: 844-851.

22. Gioacchini M, Bottoni M, Grassetti L, Scalise A, Benedetto GD (2015) A simple, reliable, and inexpensive method for seroma drainage. Arch Plast Surg 42: 361-362.

23. Vasilakis V, Cook K, Wilson D (2014) Surgical resection and scarification for chronic seroma post-ventral hernia mesh repair. Am J Case Rep 15: 526-529. 